\title{
Development of Interactive Accounting Diagnostic Test Model Based On ICT
}

\author{
Dr. Agung Listiadi, S.Pd, M.Ak \\ Surabaya State University, Indonesia
}

\begin{abstract}
Learning is an activity that is inseparable from human life. By learning humans are able to develop the potentials that they carry from birth so that later they are able to adapt themselves to meet their needs. With learning expected changes in behavior in accordance with the expected goals. But sometimes behavioral changes that are expected do not occur even if they are not in accordance with the expected goals, so that learning difficulties are born. To help solve the problem of learning difficulties including doing diagnostic tests. Diagnostic tests are used to determine students' difficulties in mastering certain competencies. As technology develops, interactive ICT-based diagnostic tests are absolutely necessary to be a solution in diagnosing learning difficulties. This research produces a product in the form of ICTbased interactive diagnostic tests. This ICT-based diagnostic test in addition to being interactive is also able to generate passing grades, set scores automatically, randomize questions automatically, and arrange variations of questions automatically. As for developing this diagnostic test model using Thiagarajan development research design that is the 4D development model consisting of the defining (Define), Designing, Developing, and Disseminate stages. Diagnostic evaluation is one of the evaluation functions that requires procedures and competencies higher than the educator role as an evaluator. Diagnostic evaluation is an evaluation that has a special emphasis on healing student learning difficulties that are not solved by the improvement formula that is usually offered in the form of evaluation formative. Diagnostic evaluation can also be interpreted as an evaluation that is used to determine student weaknesses so that based on these weaknesses can be given appropriate treatment.
\end{abstract}

Keywords: Diagnostic test, ICT

\section{Introduction}

Education is a conscious and planned efforts to created an atmosphere of learning and learned process so that students actively develop their potentials to have personality, noble character, self-controls, intelligence and the skills needed by themselves, society, nation and state (Abraham, 2006). The implementation of education must not rule out the learning process, it is intended that education is applied not merely to achieve learning outcomes, but how to obtain the learning outcomes. In addition, the education process must be student-oriented, this is done so students can develop the potential that exists in themselves (Carroll, 2011). So the educational process can shape attitudes, develop intelligence, and can develop student skills according to their needs. Therefore, learning must be complete.

According to Iserameiya (2018) The principle of complete learning is to create learners who have the ability and develop their potential, to minimize the difference between intelligent children and non-intelligent children. So that if complete learning is done under the right conditions, all students will be able to learn well, so that the learning outcomes will also be maximal.

With the talent of students for example intelligence and supported by the quality of teaching allows students to master the subject matter (Horton, 2002). If there is a miscommunication in learning, students cannot understand what is conveyed in learning, then it is likely that students cannot master the subject matter taught, so that difficulties arise in learning. In addition it takes time for students to learn, because if students are given less time than is needed to learn it, students cannot fully master the learning material. To find out the learning difficulties, diagnostic tests need to be done. diagnostic tests focus on finding the location of the 
difficulties of students in learning a subject matter so that learning improvements that will be given can be more effective towards the location of learning problems experienced by students.

Therefore a professional educator must be able to diagnose the learning difficulties to be able to help students. For this reason, efforts are needed through diagnostic tests in order to assist learning difficulties. So that diagnostic tests can help diagnose learning difficulties and can be interactive, it is necessary to touch ICT. ICT in education is very unlikely to be avoided. In the world of education, learning technology continues to experience development along with the times. In the implementation of daily learning, Information and Communication Technology is often found as a combination of audio / data, video / data, audio / video, and internet technology. Even since 1991 there has been an idea put forward about virtual classrooms by Hiltz, a researcher from America. According to the results of Hiltz's (1991) research conducted in 1991 at the University of New Jersey, created a "wallless laboratory" to develop and assess various structures for communication in learning through computer networks. Over the last few years, Hiltz (1991) has explored the use of communication in learning through computers.

IT applications / software commonly used in quiz games, with a particular design, this application can be used as an evaluation tool or preparation of tests (Slameto, 2001). The use of the wondersahre application in the evaluation of learning has not yet been found. For this reason it is necessary to have research for the development of this IT application, so that it can be used as an evaluation tool in learning, especially as an interactive diagnostic test of learning difficulties (Schinske, 2011).

Based on the research roadmap developed by the University, it is clear that research to develop interactive ICT-based diagnostic test models strongly supports the University research roadmap, especially the first target of ICT-based diagnostic tests being able to improve the quality and quantity of research for mastery of science and technology, because diagnostic tests are developed to improve the cognitive, functional and psychomotor domains containing elements of science in all fields, especially in the field of accounting learning (Belkaoui, 1992), while developing them with technology based on wondershare. The interactive ICT-based diagnostic test model also strongly supports the University's second research roadmap, which supports the implementation of national development. Where the findings in the form of interactive ICTbased diagnostic test models is an innovation in the field of education, especially learning. With the development of interactive ICT-based diagnostic test models this means participating

\section{Theoritical Framework \\ Learning Evaluation}

There are several definitions of evaluation put forward by experts as stated by Fitzpatrick et.all (2004) that evaluation is to determine the benefits or values of an object of evaluation. More broadly evaluation can be defined as identifying, clarifying and applying a number of criteria to determine the object being evaluated. [1] Evaluation is a process to determine the extent to which abilities students can achieve in the learning process. Then it was also explained that the evaluation was carried out through measurements and assessments which were the basis for improving the learning process and the learning system as a whole. [2] evaluation is a process of determining the extent to which educational goals can be achieved.

It was further explained that there are seven elements that must be carried out in the implementation of the evaluation (Zaini, 2007). The seven elements include: 1) determining the focus to be evaluated, 2) preparing evaluation designs, 3) gathering information, 4) analyzing and interpreting information, 5) preparing reports, 6) managing evaluation, and 7) evaluating for evaluation.

Stufflebeam and Shinkfield (2007) provide an evaluation definition as a systematic and focused assessment of an object. But then they add that there must be general limits and criteria that are important for consideration when assessing programs. Djaali stated that evaluation can also be interpreted as the process of evaluating something based on criteria or objectives that have been set previously, which is then followed by making decisions on the object being evaluated. As an example of project evaluation, the criteria are the objectives of the project development, whether achieved or not, whether according to plan or not, if not why and what steps will be taken next.

Likewise, Arikunto states that evaluation is an activity to gather information about the workings of something and then that information is used to determine the right alternative when making decisions. Evaluation of learning can also be intended as an organized action which is intentionally created to find out the condition of an object by means of an instrument which then the results will be compared with a benchmark so as to obtain a conclusion. Evaluation of learning has a goal, namely to find out to what extent 
the object understands the learning material provided and what percentage of students have succeeded in achieving the highest score so that educators can decide to repeat certain subject matter or not. Simply put, evaluation of learning is a systematic process that must be carried out to determine and determine the percentage of achievement level of learning objectives, and compare them, is it in accordance with what is determined? The following are some definitions of learning evaluation presented by expert figures: Through the understanding of learning evaluation a teacher will understand as well as possible, what is learning evaluation and how does it affect the learning process of a student.

Learning evaluation will help a teacher to compare, collect data, process the measured data and find out how many students have succeeded in achieving the learning objectives and how many students must be guided, taught and educated so they can achieve the expected and predetermined goals. Although at first glance the understanding of evaluation and learning evaluation looks similar, it does not mean that understanding and deepening can be done in the same way, the teacher must understand all aspects that distinguish between evaluation and learning evaluation so that there is no error when the plan to conduct an evaluation of learning will begin.

\section{Diagnostic Test}

Learning development is something that must be done by every teaching staff so that the students can follow each learning process well (Moorable, 2000). As we all know that currently various technological devices have been widely circulating in the market which takes up a lot of time each person is no exception for students. Sometimes the presence of these technological devices can have a positive impact and can be used to support the creation of a learning process which is good, but not infrequently the presence of these technological devices has a bad impact because students lack the maximum learning, or can also have good learning but do not utilize the technological devices so as to make students less able to adapt as they go through life in an increasingly modern world (Dyson, 2014). And for this reason, for the sake of creating an optimal learning, an educator is important to carry out the evaluation process of learning outcomes.

The formative evaluation function is limited to assessing the achievement of specific instructional goals that have been formulated by the teacher in the teaching administration program (learning unit). In carrying out its functions, formative tests or evaluations do not encompass fundamental learning difficulties. Weaknesses of formative evaluation in finding learning difficulties can be caused by improper use or because of the characteristics of formative tests themselves which do not allow finding the reasons underlying student learning difficulties. To explore these causes requires a more careful monitoring tool, namely a diagnostic test of learning outcomes.

When a teacher is implementing a particular learning unit some of his students have difficulty achieving the specified learning goals despite the remedial program, in the mind of a teacher may appear the question: "Why can't my students reach the learning goals? Do they encounter any obstacles / difficulties? Where do the difficulties / obstacles arise? How do they overcome them? ", When students experience problems / obstacles in learning, and are so difficult to overcome with remedial teaching (Silberman, 2001), the teacher should provide diagnostic tests. Diagnostic tests are intended as a more in-depth study of students' learning difficulties. A diagnostic test is usually a test that is made with a sufficient number of item items on a specific / specific material (Khafid, 2007). Item items are made with very little difference in variation from one item to another so that the causes of learning difficulties / obstacles can be detected.

Diagnostic assessment is an assessment that aims to see the weaknesses of students and the factors causing it. This assessment is carried out on a necessity such as remedial evaluation of teaching (Dale, 1859). The main target of learning diagnostic tests is to find errors or misconceptions and process errors that occur in students when studying a particular learning topic. For example in arithmetic, attention is more focused on the ability to do the calculation process and understand the basic concepts of addition or subtraction than the final result obtained by students.

\section{ICT application}

As an alternative to making interactive learning multimedia in addition to using Macromedia Flash is to use Power point. Besides its ease of use and easy to learn power point also provides a good display, especially Power Point. But there are some disadvantages to Power Point compared to using Flash, namely the absence facility for making quizzes or evaluations. But this can now be overcome by using additional third-party ICT output software, ICT Google Drive. 
Evaluation of learning at a place to learn is usually done in writing / conventionally. To make learning evaluation more interesting for students, it is necessary to have a touch of ICT. In this 21 st century almost every time humans use ICT to help facilitate their lives (Arikunto, 2013). In the case of learning in the 21st century it should also take into account the development of IT. One of the activities in learning is the evaluation of learning. Evaluation of learning is often an activity that is less attractive to students (Jones, 2008). To make evaluations of learning interesting it is necessary to touch ICT. As an alternative to making interactive learning multimedia especially in terms of learning evaluation besides using Macromedia Flash, ICT can be used. Besides being easy to use and easy to learn, ICT also provides a good display. By using ICT, it is possible to arrange questions interactively which can be run online or offline.

In Google Drive it provides various types of question types. Not all types of questions are used; to use it needs to be adjusted to the subject matter. IT Google Drive is software for making questions, quizzes or tests online (web-based). The use of Google Drive IT in making these questions is very familiar / user friendly, so it is very easy to use and does not require programming language skills that are difficult to operate. The results of questions, quizzes and tests created / compiled with this software can be stored in a Flash format that can stand stand alone on the website. With Google Drive IT, users can create and arrange different forms and levels of questions, namely the form of true / false questions (true / false), multiple choices (multiple choices), filling words (fill in the blank), matching (matching), Quizzes with drawing areas and more. Even with Google Drive IT you can also insert various images (images) and Flash files (Flash movie) to support students' understanding of the problem solving. Some of the facilities available in the Google Drive IT, apart from the ease of use (user friendly) of the questions generated (Nur, 2000) include (1). Feedback facilities based on the response / answers of the test participants, (2). Facilities that display test results / scores and steps to be followed by test participants based on the responses / answers entered, (3). Facility of changing text and language on buttons and labels according to the wishes of the question maker, (4). Facility to include sound and color in the matter in accordance with the wishes of the question maker, and (5). Hyperlink facility; i.e. send test results to an email or LMS. (6) Facilities for making random questions, (7) Security facilities with User accounts / passwords, (8) Facilities for display settings that can be modified.

\section{Research Methods}

Development models can be procedural, conceptual and theoretical models. Procedural models are descriptive models, which outline the steps that must be followed to produce products. The application of this development model is a product in the form of a matter of national exam simulation based on ICT applications online. The development model used is the development model according to Thiagarajan which is a $4 \mathrm{D}$ (four $\mathrm{D}$ method) development model consisting of the defining stage (Define), the design stage (Design), the development stage (Develop), and the deployment stage (Disseminate). Dissemination was not carried out due to limited connectivity and the ability of researchers. Described as follows: The purpose of the defining stage is to establish and define learning requirements. In this stage the researcher will analyze the requirements needed before designing the national exam simulation material based on online with IT applications. The thing to consider is the curriculum that is needed in a development. In this development what is used is the curriculum based on scientific at the level which is the trading company accounting cycle.

Analysis of student characteristics is carried out at the beginning of planning which aims to determine the characteristics possessed by students in accordance with the IT-based interactive diagnostic test design that was developed. Student characteristics include academic ability, age and maturity level and student experience. Based on these characteristics it is expected that the design of interactive IT-based diagnostic test materials developed is suitable for use as student teaching materials. Subjects that were subjected to testing the interactive Google Drive-based diagnostic test material were class of accounting students. The task analysis here is to prepare accounting material on the basic competencies of the trading company accounting cycle which will be delivered through teaching materials. The task analysis is carried out by detailing the contents of the material contained in the developed teaching material which is material in accordance with the basic competencies of the trading company accounting cycle. Concept analysis is done by identifying the main concepts that will be developed, systematically structuring and detailing concepts that are relevant to the material to be developed. Teaching material material developed is adjusted to learning material that refers to namely compiling the trading company accounting cycle. Analysis of 
learning objectives is specifically done to convert the results of task analysis and concept analysis into learning objectives. The results of the formulation of learning objectives will be the basis in the preparation of material, and electronic teaching materials in the form of interactive IT-based diagnostic test materials developed in accounting learning.

The design phase was carried out to design materials in the form of IT-based interactive diagnostic tests that were developed on the basic competencies of the trading company accounting cycle for accounting students. Activities carried out at this stage were: Selection of interactive drive based Google Drive diagnostic test material developed. In the selection of an electronic format in the form of interactive Google-based interactive diagnostic test materials, it can be done by selecting materials, forms of evidence / financial transaction documents. Initial Design IT-based interactive diagnostic test materials are developed. Learning is related to the performance of Google Drive-based interactive diagnostic test materials. In accordance with the drawing chart of the 4D model device development flow, then at this stage the researcher asked for input from the experts / experts in the field of graphic design and learning. The purpose of this stage is to study and validate learning tools and teaching materials for interactive Google Drive based diagnostic tests. Through this stage will get revisions depending on the advice / input from experts. This stage is the spread of the results of printed products in the form of interactive IT-based diagnostic test materials developed, through workshops.

Product trials are conducted as a benchmark of success in developing a teaching material product in the form of interactive IT-based diagnostic test material that is developed on the basic competencies of the trading company accounting cycle. The benchmarks are measured from suggestions and responses through an assessment of IT-based interactive diagnostic tests, then revised to achieve the feasibility of the product to be developed. The subjects used in the trial development of IT-based interactive diagnostic test materials that were developed in the basic competencies of trading company accounting.

Data obtained from filling out the questionnaire were analyzed descriptively quantitatively using percentages. This technique is carried out by giving statements about ICT-based interactive diagnostic test materials that are developed based on the scores given to exam simulation materials based on online with the ICT application. The value of IT-based interactive diagnostic test material developed on the basic competencies of trading company accounting cycles.

\section{Analysing and Result}

Presentation of the results of research and development aims to answer the problem formulation mentioned above. The data that will be presented is a series of results of the development of diagnostic tests that have been developed, on the subject matter of the trading company accounting cycle at the accounting student. This development uses a development model according to Thiagarajan, which is 4D (Four D Models) consisting of the stages of define, design, develop, and disseminate. However, in this study only carried out until the development stage (develop) only because of the limitations of researchers. The results of the development of diagnostic tests that have been developed, on the subject matter of the accounting cycle of trading companies are as follows: At this defining stage, researchers define and define learning requirements. The researcher analyzes the requirements needed before designing an ICT-based diagnostic test. This define stage includes five main steps, namely front-end analysis, student analysis (learner analysis), task analysis, concept analysis, and formulation of learning objectives (specifying instructional objectives). The front end analysis is done by analyzing the phenomena that occur in the field, especially in accounting student. Researchers found several phenomena that occur, such as most students consider and experience difficulties in the subject matter of the trading company accounting cycle. Student understanding is also lacking due to inadequate teaching materials available, in the sense that the material presented in the teaching material is available briefly and does not support the application of the scientific approach in the implementation of the Curriculum.

Meanwhile, according to students, in understanding the subject matter of the use of special journals other teaching materials are needed. However, students are also less active in their own activities looking for references to other learning resources, for example from the internet. It is these factors that have hampered the implementation of the Curriculum that was running less optimally. Based on the phenomena and problems that occur, researchers have an idea to develop a diagnostic test that can be used to determine the location of student learning difficulties on a particular material. Student analysis is carried out by researchers by analyzing student characteristics, which include academic ability, age, motivation for the subject, as well 
as student's initial knowledge. The subjects that were subjected to the trial of the Scientific Approach-based print teaching materials were class of accounting. In general, class of accounting have good motivation to learn about the material learned in class. Cognitive ability continues to develop during the age of accounting student (adolescents). Cognitive changes during the accounting student age lead to increased potential. Sometimes some cognitive abilities decline with age. Accounting student age adolescents who are in the search and want to determine their identity have an attitude that is too high to assess themselves or vice versa. They have not really understood the social norms that apply in social life. Both can cause social relations that are less harmonious, because they are difficult to accept sexual norms with conditions in the group or society. Opposition and awkwardness in relationships will hurt both parties. Therefore, efforts are needed to develop adolescent social relations starting from the family, a place to learn and community environment.

There are changes that are universal in adolescence at the age of accounting student, namely the height of emotions whose intensity depends on the level of physical and psychological changes, body changes, changes in interests and roles expected by certain social groups to play which then cause problems, changing interests, behavior and values, are ambivalent about change. These changes ultimately affect their physical, cognitive, affective, and psychomotor development. In connection with the emotions of teenagers who tend to be daydreaming and difficult to guess, the only thing educators can do is treat students like adults who are full of sense moral responsibility. One fundamental way is to encourage them to compete with themselves. It must be realized that adolescents at the age of accounting student are in a state of confusion and difficult to predict behavior. In many ways, he relies on parents about physical needs and feels an obligation to the care they provide when he is unable to look after himself. However, he also felt that he wanted to be free from his parents' authority to become an independent adult. That triggers a conflict with parents. If this kind of friction occurs, teenagers at the age of development may feel guilty, which in turn can increase the gap between him and his parents. A student who feels confused about the condition may feel the need to share his suffering, including his personal secrets to others. Therefore, a supervisor should appear functional and act like a sympathetic listener.

In a trading company, there is an additional asset account, namely Merchandise Inventory. The main income of a trading company is the sale of merchandise called sales revenue, or commonly referred to as sales. In the case of expenses, the trading company has two groups of expenses called cost of goods sold and operating or operational expenses. Cost of goods sold is the total cost of goods sold during the period. This charge is directly related to the revenue recognized from the sale of goods. The two new accounts above determine the amount of profit or loss of a trading company. This is because both accounts are directly related to the flow of cost of goods or the cost of goods purchased which in turn (when the inventory is sold) will be the cost of goods sold. The cost flow of a merchandising company is as follows: the initial inventory of merchandise plus the cost of purchased goods will form the acquisition cost of goods available for sale. Furthermore, the cost of goods available for sale will be the cost of goods sold (for goods sold this period) or commonly referred to as cost of goods sold and as ending inventory (items remaining at the end of the period and will be sold in the next period).

Given the importance of determining the cost of inventory at a trading company, we will discuss inventory recording systems such as the perpetual inventory system and the periodic inventory system. In a periodic inventory system, the company does not hold a detailed record of the inventory it has throughout the period. Determination of the cost of goods sold is done at the end of each period, which is why this system is called periodic. At the end of the period, the company makes a physical calculation of the inventory that is still in stock (unsold goods) to determine the cost of inventory.

Before designing this ICT-based diagnostic test, there are several phenomena and problems that have been previously analyzed by researchers (front end analysis). Based on the front-end analysis, the researcher has an idea to develop an ICT-based diagnostic test. Researchers have designed teaching materials that are considered capable of meeting students' learning needs, so that learning activities that use the Curriculum can be carried out maximally. The design phase in the process of making printed teaching materials aims to design ICT-based diagnostic tests as evaluation materials supporting the implementation of the Curriculum on the subject matter of the accounting cycle of trading companies in accounting student. Broadly speaking, this design phase includes two steps, namely the selection of teaching material formats, layout of teaching materials and the initial design of teaching materials. 
In accordance with the drawing chart of the 4D model device development flow, then at this stage the researcher asked for input from the experts / experts in the field of graphic design and learning. The purpose of this stage is to study and validate ICT-based learning tools and diagnostic tests. Through this stage will get revisions depending on the advice / input from experts. So that the direction of the research is in accordance with the planning, an instrument was developed to validate the results of the ICT-based learning kit and diagnostic test design. The instruments compiled are as follows: The results of the validation of the ICT-based diagnostic questions on the material managing trading company transaction documents show that the average score according to the material expert Validator is $92 \%$ with a very decent category and the media expert validator is $91 \%$ with a very feasible category. The first aspect regarding the material gets very decent criteria of $92 \%$. This is because the material aspects listed in the ICT-based diagnostic problems are in accordance with the material being taught, namely managing transaction documents. In this ICT-based diagnostic problem, the items are developed in accordance with Competency Standards, Basic Competencies and Learning Objectives that were expected before. In addition, the items have covered all the material Managing Transaction Documents starting from the understanding, the field of specialization and position in accounting, basic accounting equations, financial statements accounting basic equations, proof of transactions, debit and credit mechanisms, and equipment needed and store evidence of company transactions. The items vary from difficult to easy and allocations are provided according to the number of questions. This is because in the construction aspect, the item is appropriate for measuring every aspect of thinking as mentioned in the specific instructional objectives. In the ICT-based diagnostic questions developed has the title Managing Transaction Documents, for the length of time used to work adjusted to the number of questions and the time will follow during the test. It aims to remember students about the time they have because when the time is up then the computer assumes that students have finished working. After validation by the material expert, then the questions will be tested to find out the quality of the questions. Based on the explanation of the quality of the questions in the form of validity, reliability, level of difficulty, different power and deception effectiveness. From the results of these data, there are questions that are used because they meet the quality of good questions, so as to produce an ICT-based diagnostic problem that is validated by media experts and material experts and has good quality. Most students gave a positive response or response to every aspect that was asked on the student questionnaire response sheet to the ICTbased diagnostic questions developed by researchers. From the results of limited trials, the data presented above were analyzed using descriptive percentage analysis techniques. Where descriptive percentage analysis is a method used to convert quantitative data into percentage form which is then interpreted with qualitative sentences which consist of assessment of problem construction and implementation of ICT-based diagnostic problems. Analysis of student response data is described as follows: Based on the analysis of student opinion questionnaire limited trials can be seen from the results of the student opinion questionnaire. From the aspect of constructing the questions, it is obtained the criteria of "very feasible" with a percentage of $85 \%$. Overall analysis of the results of limited trials of ICT-based diagnostic questions from students' opinions obtained an average percentage of $85 \%$, then the development of ICT-based learning diagnostic questions for trading company cycle material for accounting student was declared "very feasible".

ICT-based diagnostic problems in the trading company cycle material make students more motivated to be active. Thus it can be seen the existence of ICT-based diagnostic problems in the material cycle of trading company accounting in class accounting student developed can make students more motivated in learning and trying to do the test questions correctly, reduce cheating-cheats during the test, and help educators in conducting ICT-based diagnostic tests more effectively and efficiently. The results of the research development of ICT-based diagnostic questions on accounting student can run well and get good responses. Using diagnostic questions can make it easier for educators to assess students. The development of ICT demands a change in the conventional education paradigm that has the characteristics of educator-centered education but in ICT-based education emphasizes student centered education and mastery of ICT.

\section{Conclusion}

The research resulted in ICT-based diagnostic test questions that can be used to support the application of a scientific approach in the implementation of the Curriculum. Research has so far reached the develop stage, namely the third stage of the four stages as outlined in the research design. In the third stage (develop) in this study, has succeeded in formulating an instrument that will be used to validate the findings. Validation is absolutely necessary to perfect the design / product that has been produced. 


\section{Future considerations}

Collaboration with experienced media experts is needed in evaluating findings / products, so that deficiencies in the product can be identified to be corrected immediately. A trial is needed through experimental research to get responses from research subjects, namely students as users of this product. Disseminate is needed after the product is perfected so that the maximum use of the product can be known from its users.

\section{References}

1. Abraham, A. 2006. Perceptions of the Linkages between teaching Contexts, Approaches to Learning and Outcomes. Research Online institutional repository for the University of Wollongong.

2. Arikunto, Suharsimi. 2013. Educational Evaluation Basics. Jakarta: Bumi Aksara.

3. Belkaoui, A. R. (1992). Accounting Theory. $3^{\text {rd }}$ ed. New York : $5^{\text {th }}$ ed. Boston.

4. Carroll, Margaret Kelly. 2011. Fun and Games in Higher Education. Eastern Education Journal, Vol 40(1) spring. pp. $23-32$.

5. Dale, E.1859. Audiovisiual methods inteaching. $3^{\text {rd }}$ ed. New York : Holt.

6. Dyson, B. 2014. Quality Physical Education : A commentary on Effective Physical Education Teaching. Research Quarterly for Exercise and Sport. 92 (2). pp 144-152.

7. Fitzpatrick, J. L., Saners, J. R., \& Worthen, B. R. (2004). Program evaluation: Alternatives, approaches, and practical guidelines $\left(3^{r d}\right.$ Ed.). Boston: Pearson Education Inc.

8. Hiltz, Starr Roxanne. 1991. The "Virtual Classroom": Using Computer-Mediated Communication for University Teaching. Journal of Communication. Vol 36. Issue 2. https://doi.org/10.1111/j.14602466.1991.tb01427.x.

9. Horton, William. 2002. Speakers_experiences and audience design: knowing when and knowing how to adjust utterances to addressees. Journal of Memory and Language, 47 (2002) 589-606.

10. Iserameiya F.E, Ibeneme O.T 2018. Effect of Mastery Learning Strategy on Junior Secondary School Students' Academic Achievement in Basic Technology in Edo State, Nigeria. International Journal of New Technology and Research (IJNTR), Volume-4, Issue-3. pp 95-101.

11. Jones, Karrie. 2008. Making Cooperative Learning Work in the College Classroom: An Application of the 'Five Pillars' of Cooperative Learning to Post-Secondary Instruction. The Journal of Effective Teaching, Vol. 8, No. 2. pp 61-76.

12. Khafid, Muhammad, 2007. Factors Affecting Difficulty in Learning Accounting. Journal of Economic Education, Vol 2 No.1.

13. Morable, Linda. 2000. Using Active Learning Technique. Exclusive opyright is retained by the U.S. Department of Education, the Texas Higher education Coordinating Board, and Richland College.

14. Nur, Muhamad et al. (2000). Cooperative Learning. Surabaya: Unesa University Press.

15. Silberman, Mel. 2001. "Active Learning: 101 Active Learning Strategy". Translated by Sarjuli et al. Yogyakarta: Yappendis.

16. Stufflebeam, D. L., \& Shinkfield, A. J. (2007). Evaluation Theory, Models and Applications. San Francisco, CA: Jossey-Bass.

17. Schinske, Jeffrey N . 2011. Taming the Testing/Grading Cycle in Lecture Classes Centered Around Open-Ended Assessment.. National Science Teachers Association (NSTA).Reprinted with permission from Journal of College Science Teaching, Vol. 40, No. 4.

18. Slameto. 2001. Education Evaluation. Jakarta: Bumi Aksara.

19. Uno, Hamzah (2006). Theory of Motivation and Its Measurement Analysis in the Field of Education. Jakarta: Bumi Aksara.

20. Zaini, Hisyham. 2007. Active Learning Strategy. Yogyakarta : CTSD. 